\title{
Formas de carbono em latossolo sob sistemas de plantio direto e integração lavoura-pecuária no cerrado, Goiás
}

\section{Forms of carbon in an oxisol under no-tillage and crop-livestock integration systems in the cerrado, Goias State, Brazil}

\author{
Régis Pinheiro Martins Bezerra ${ }^{1}$; Arcângelo Loss²; Marcos Gervasio Pereira ${ }^{3 *}$; \\ Adriano Perin ${ }^{4}$
}

\section{Resumo}

\begin{abstract}
O sistema plantio direto (SPD) e mais recentemente, a integração lavoura-pecuária (ILP) são muito utilizados para produção de grãos no bioma Cerrado. Neste, a matéria orgânica do solo (MOS) é um dos principais componentes responsáveis pela manutenção da qualidade dos solos tropicais. Este trabalho objetivou quantificar os teores de carbono orgânico total (COT), nitrogênio total (N-total), carbono solúvel em água (CSA) e carbono das frações húmicas em áreas com diferentes sistemas de uso do solo no Cerrado goiano. Os sistemas agrícolas utilizados foram: ILP (milho+braquiária/feijão/algodão/soja) e SPD (girassol/milheto/soja/milho) e como referência, área de vegetação nativa de Cerrado (Cerradão). Foram coletadas amostras de terra nas profundidades de 0-10; 10-20; 20-30 e 30-40 cm. Foram determinados os teores de COT, N-total, CSA, carbono da fração humina (C-HUM), fração ácido húmico (C-FAH) e fração ácido fúlvico (C-FAF). A área de Cerradão apresentou os maiores teores de COT, N-total, C-HUM e C-FAH na camada superficial $(0-10 \mathrm{~cm})$. Os teores de CSA e das frações húmicas da MOS apresentaram diferenças significativas entre os sistemas de uso do solo e as profundidades de amostragem. Os maiores teores de C-FAH foram encontrados na área de ILP, nas camadas de 0-10 e 20-30 cm. Os sistemas de ILP e SPD não apresentaram diferenças para o COT e N-Total, exceto para $\mathrm{N}$ na camada de $20-30 \mathrm{~cm}$. O sistema de ILP favorece a formação do C-HUM em comparação ao SPD. O sistema de ILP acarreta em menores teores de CSA e maiores de C-FAF quando comparado com o SPD, que apresenta maiores teores de CSA e C-FAH. O uso do CSA e carbono das frações húmicas foi mais eficiente para identificar diferenças provenientes dos sistemas de uso do solo avaliados (SPD, ILP e Cerradão) quando comparado ao COT, para as condições edafoclimáticas do presente estudo.

Palavras-chave: Carbono orgânico total, carbono solúvel em água, carbono das frações humina, ácidos húmicos e fúlvicos
\end{abstract}

\footnotetext{
Abstract

The no-tillage system (NTS) and more recently, the crop-livestock integration (CLI) are very used for grain production in the Cerrado biome. This, the soil organic matter (SOM) is one of the main components responsible for maintaining the quality of tropical soils. This study aimed to quantify the

${ }^{1}$ Discente do Curso de Pós-Graduação em Solos e Nutrição de Plantas, Dept ${ }^{\circ}$ de Ciência do Solo, Universidade Federal do Ceará, UFC, Fortaleza, CE. E-mail: regispmb@yahoo.com.br

${ }^{2}$ Prof. Adjunto, Centro de Ciências Agrárias, Dept ${ }^{\circ}$ de Engenharia Rural, Universidade Federal de Santa Catarina, UFSC, Florianópolis, SC. E-mail: arcangeloloss@yahoo.com.br

${ }^{3}$ Prof. Associado IV, Dept ${ }^{\circ}$ de Solos, Instituto de Agronomia, Universidade Federal Rural do Rio de Janeiro, UFRRJ, Seropédica, RJ. E-mail: gervasio@ufrrj.br

${ }^{4}$ Prof. D3, Instituto Federal de Educação, Ciência e Tecnologia, Campus Rio Verde, GO. E-mail: perinrj@yahoo.com.br

* Autor para correspondência
} 
levels of total organic carbon (TOC), total nitrogen (total N), water soluble carbon (WSC) and carbon of humic fractions in areas with different land use systems in the Cerrado of Goias. The farming systems were used: CLI (brachiaria + corn/beans/cotton/soybean) and NTS (sunflower/millet/soybean/corn) andas a reference, area native Cerrado vegetation (Cerradão). We collected soil samples at $0-10,10-$ 20, 20-30 and 30-40 cm. The contents of TOC, total N, WSC, humin fraction carbon (C-HUM), humic acid fraction (C-HAF) and fulvic acid fraction (C-FAF). The area of Cerradão had the highest TOC, total N, C-HUM and C-FAH in the surface layer $(0-10 \mathrm{~cm})$. The levels of WSC and humic fractions of SOM showed significant differences between the systems of land use and sampling depths. The highest levels of C-HAF were found in the area of CLI, at 0-10 and 20-30 cm. The CLI systems and NTS did not differ for the TOC and total $\mathrm{N}$ except for $\mathrm{N}$ in layer $20-30 \mathrm{~cm}$. The system CLI favors the formation of C-HUM compared to the NTS. The CLI system leads to lower levels of WSC and higher C-FAF compared with the NTS, which has higher levels of WSC and C-FAH. The use of WSC and carbon of humic fractions was more efficient to identify differences from the land use systems evaluated (NTS, CLI and Cerradão) when compared to the TOC for the climatic conditions of this study.

Key words: Total organic carbon, water soluble carbon, carbon fractions humin, humic and fulvic acids

\section{Introdução}

O bioma Cerrado é o segundo maior em extensão geográfica e apresenta uma dinâmica acentuada em termos de sazonalidade (verão quente e úmido e inverno frio e seco) e por meio de ações antrópicas (BUSTAMANTE et al. 2006; SANO et al., 2007), sendohojeuma dasmaioresáreascultivadasdomundo (SIQUEIRA NETO et al., 2009), principalmente com culturas de grãos, tais como feijão, milho, girassol e soja. Entretanto, o monocultivo e práticas culturais inadequadas têm promovido diminuição da produtividade, degradação do solo e dos recursos naturais (BERNOUX et al., 2004). A reversão desse quadro pode ser alcançada através da integração lavoura-pecuária (ILP), principalmente quando associada ao sistema plantio direto (SPD), pois ambos contemplam o revolvimento mínimo do solo e a prática de rotação de culturas, com ênfase em gramíneas e leguminosas (MORETI et al., 2007; MACEDO, 2009; CARVALHO et al., 2010; LOSS et al., 2011).

A conversão de áreas nativas em agricultáveis é normalmente acompanhada pelo declínio dos teores da matéria orgânica do solo (MOS) e degradação da estrutura do solo (RESCK et al., 2008). Além de alterações na agregação do solo, tem-se efeitos negativos nas concentrações de nutrientes do solo (ASHAGRIE et al., 2007), no armazenamento de água (RESCK et al., 2008) e na emissão de gases de efeito estufa (LAL, 2006).

A maioria dos estudos sobre o acúmulo de carbono em solos de Cerrado sob diferentes manejos do solo elencam principalmente os teores e estoques de carbono orgânico total do solo (COT) (BERNOUX et al., 2004; FONTANA et al., 2006; BLANCHART et al., 2007; SIQUEIRA NETO et al., 2009; PEREIRA et al., 2010, COSTA JUNIOR et al., 2011). Entretanto, dependendo do tempo de adoção dos sistemas de manejo adotados muitas vezes não é possível identificar diferenças entre os sistemas avaliados somente por meio da análise da variação dos teores de COT. Assim, é necessário obter maior volume de dados sobre o padrão das diferentes frações que compõem o COT, tais como o carbono solúvel em água (CSA) e carbono das frações húmicas, para melhor recomendação do uso e manejo desses solos.

O CSA é a forma de carbono mais ativa, lábil, facilmente perdida, e tem em sua constituição carboidratos, ácidos orgânicos de baixo peso molecular e uma pequena fração de ácidos fúlvicos (STEVENSON, 1994; ZECH et al., 1997). Segundo Oliveira Junior et al. (2008), as formas de CSA no solo e a sua concentração são reguladas por atributos tais como qualidade e teor de MOS, acidez do solo (ou alcalinidade), disponibilidade de nutrientes, mineralogia e fatores relacionados à dinâmica da comunidade microbiana do solo. Avaliando 
a concentração de CSA em diferentes sistemas de produção de milho em Latossolo Vermelho, Jaboticabal, SP, Souza e Melo (2003) encontraram diferenças entre os sistemas de produção. Os autores verificaram que o cultivo do milho sobre crotalária em sucessão no SPD e rotação com a soja no sistema de preparo convencional propiciaram maiores valores de CSA quando comparados com SPD em sucessão a mucuna e feijão guandu e com pousio após o cultivo de milho em sistema de preparo convencional.

Estudos da MOS através da quantificação do carbono das frações húmicas têm sido conduzidos para o entendimento da pedogênese (FONTANA et al., 2011), da melhoria de propriedades físicas do solo (LOSS et al., 2010), da diminuição da fixação do fósforo (FONTANA et al., 2008), do impacto da agricultura na qualidade do solo (MENDONZA et al., 2000; CUNHA et al., 2001; OLIVEIRA JUNIOR et al., 2008; FONTANA et al., 2010). Avaliando a quantificação do carbono das frações húmicas em diferentes sistemas de uso do solo em Montividiu, GO, Rossi et al. (2011) verificaram que o carbono das frações húmicas foi útil para identificar mudanças promovidas pelos diferentes usos do solo no Cerrado goiano sobre SPD. Os autores constataram que o SPD com braquiária aumentou os teores de carbono das frações húmicas quando comparado com o SPD com sorgo.

Desta forma, este trabalho teve como objetivos quantificar os teores de carbono orgânico total, nitrogênio total, carbono solúvel em água e carbono das frações húmicas em áreas com diferentes sistemas de uso do solo no Cerrado goiano.

\section{Material e Métodos}

O presente estudo foi realizado na Fazenda Vargem Grande, pertencente à Agropecuária Peeters,

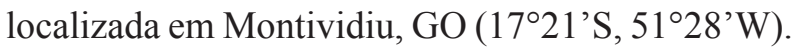
O clima da região apresenta duas estações bem definidas, caracterizada por um período de seca (entre os meses de maio a setembro) e por outro chuvoso (entre os meses de outubro a abril). A temperatura média anual varia entre 20 e $28^{\circ} \mathrm{C}$ (Figura 1).

Figura 1. Valores médios de precipitação pluviométrica e temperatura no ano de 2008.

$\square$ Precipitação $\_$Temperatura máxima $\bullet$ Temperatura mínima

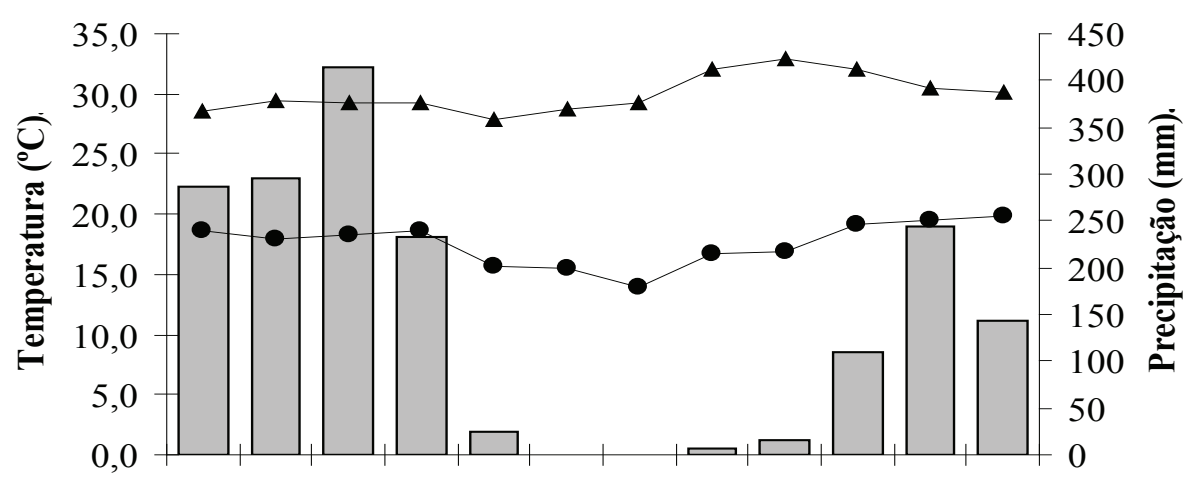

Jan Fev Mar Abr Mai Jun Jul Ago Set Out Nov Dez

Meses

Fonte: (LOSS, 2011). 
O solo das áreas avaliadas foi classificado como Latossolo Vermelho Distrófico apresentando textura muito argilosa e relevo plano (SANTOS et al., 2006). Na composição mineralógica da fração argila há predomínio de gibbsita, caulinita e hematita (SIQUEIRA NETO, 2006). Alguns atributos químicos e físicos do solo nos diferentes sistemas e profundidades de uso do solo são mostrados na Tabela 1.

Tabela 1. Caracterização química da camada superficial ${ }^{1}$ do Latossolo Vermelho nos diferentes sistemas de uso do solo no Cerrado goiano.

\begin{tabular}{cccc}
\hline \multirow{2}{*}{ Atributos avaliados } & \multicolumn{3}{c}{ Sistemas Avaliados } \\
\cline { 2 - 4 } & SPD & ILP & Cerradão \\
\hline $\mathrm{pH}$ & 6,3 & 6,3 & 5,4 \\
$\mathrm{Ca}\left(\mathrm{cmol}_{\mathrm{c}} \mathrm{dm}^{-3}\right)$ & 3,6 & 4,1 & 1,2 \\
$\mathrm{Mg}\left(\mathrm{cmol}_{\mathrm{c}} \mathrm{dm}^{-3}\right)$ & 2,5 & 2,3 & 1,8 \\
$\mathrm{~K}\left(\mathrm{mg} \mathrm{dm}^{-3}\right)$ & 87,7 & 83,8 & 58,5 \\
$\mathrm{P}\left(\mathrm{mg} \mathrm{dm}^{-3}\right)$ & 8,1 & 12,1 & 1,9 \\
$\mathrm{Al}\left(\mathrm{cmol} \mathrm{dm}_{\mathrm{c}}^{-3}\right)$ & 0,11 & 0,10 & 0,70 \\
Argila $\left(\mathrm{g} \mathrm{kg}^{-1}\right)$ & 660 & 655 & 620 \\
Silte $\left(\mathrm{g} \mathrm{kg}^{-1}\right)$ & 126 & 115 & 130 \\
Areia $\left(\mathrm{g} \mathrm{kg}^{-1}\right)$ & 214 & 230 & 250 \\
\hline
\end{tabular}

= profundidade de 0-20 cm; $\mathrm{pH}=\mathrm{pH}$ em água $\mathrm{P}=\mathrm{P}-\mathrm{Mehlich}^{-1} ; \mathrm{K}=$ potássio; $\mathrm{Ca}=$ cálcio; $\mathrm{Mg}=$ magnésio; $\mathrm{Al}=$ alumínio trocável; $\mathrm{SPD}=$ girassol/milheto/soja/milho; ILP $=$ milho+ Brachiaria $/$ feijão/algodão/soja.

Fonte: Elaboração dos autores.

Anteriormente à implantação dos sistemas de uso do solo avaliados, existia uma cobertura vegetal de Cerradão que foi derrubada em 1975, sendo em seguida feita aração e gradagem niveladora (sistema de preparo convencional - SPC) para implantação de pastagens - braquiária (Urochloa decumbens (Stapf) R. D. Webster). A pastagem implantada sobre a área de Cerradão permaneceu por 10 anos, sob uso contínuo, até 1985. Em seguida, as áreas foram cultivadas com grãos (milho, feijão, soja e girassol) sob SPC (aração e gradagem niveladora) até o ano de 1991. Posteriormente, foi implantado o Sistema de Plantio Direto (SPD) com rotação de culturas (milho, soja, algodão, feijão) e, a partir de 1999, parte do SPD foi transformado em Integração Lavoura-Pecuária (ILP). Portanto, as áreas avaliadas vêm sendo conduzidas em SPD com as mesmas rotações de culturas, sendo SPD somente (1991 a 2008) e ILP (1999 a 2008) (Figura 2). Os sistemas de uso do solo estavam sob as mesmas condições topográficas e edafoclimáticas, diferindo apenas no sistema de uso da terra. 
Figura 2. Histórico dos usos e processos de mudança do uso da terra, com as respectivas datas de implantação, na Fazenda Vargem Grande da Agropecuária Peeters, em Montividiu, GO.

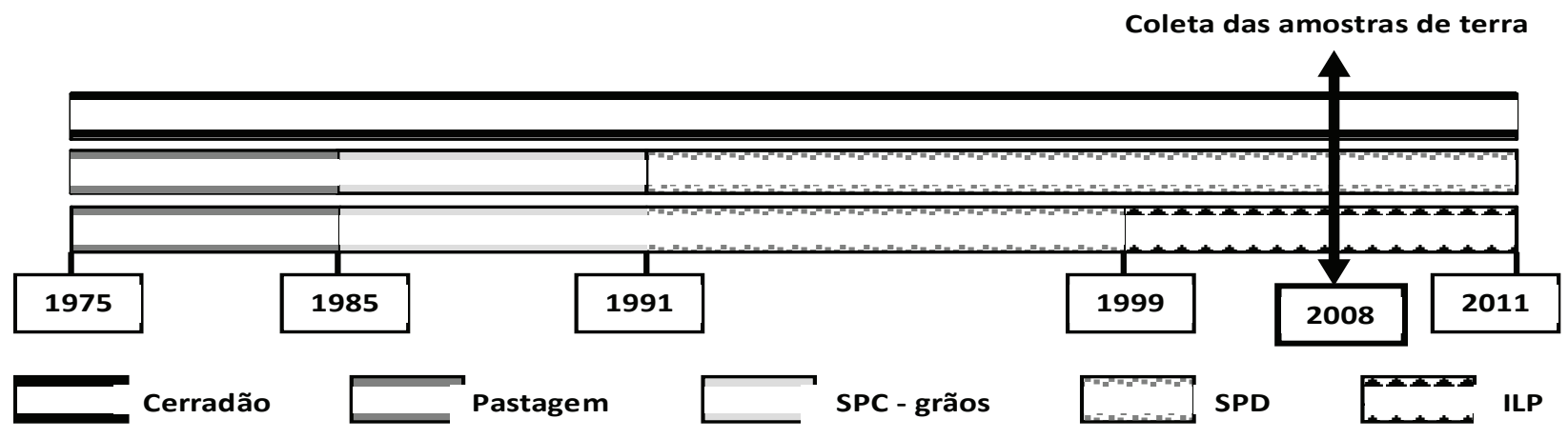

Fonte: (LOSS, 2011).

Os sistemas avaliados consistiram de duas áreas cultivadas em SPD por 17 anos (1991 a 2008): uma somente com rotação de culturas (girassolmilheto-soja-milho), e outra com braquiária ( $U$. ruziziensis) em consórcio ao milho safrinha, para intensificar a produção de palhada no período seco do ano (milho-braquiária-feijão-algodão-soja). Nesta área foi utilizado o sistema de ILP (9 anos: 1999 a 2008), com o milho e a braquiária semeados simultaneamente (braquiária na entrelinha). Após a colheita do milho, nesta área foram introduzidos os bovinos e mantidos por 90 dias (2,0 UA/ha ${ }^{-1}$ - Unidade Animal, durante os meses de julho a setembro). Após a retirada do gado, na ocasião das primeiras chuvas, foi realizada adubação em cobertura sob braquiária com $200 \mathrm{~kg} \mathrm{ha}^{-1}$ do formulado N P K (20:00:20). Após a rebrota das soqueiras, quando a área estava totalmente coberta pela capineira, foi realizada a dessecação, para em seguida, o plantio do feijão. Uma área de Cerrado natural preservado (Cerradão) foi considerada como condição original do solo.

Nas áreas sob ILP e SPD, aplicaram-se, em 2005, 3,60 e 2,90 $\mathrm{Mg} \mathrm{ha}^{-1}$ de calcário dolomítico, com PRTN $=70 \%$, para a elevação da saturação por bases para $70 \%$ e. $60 \%$, respectivamente. A sequência de culturas e adubações utilizadas nas duas áreas, desde o ano de 2002 até 2008, é apresentada na Tabela 2. Durante os meses de agosto, na área de SPD, foi realizada a semeadura do milheto com a finalidade de produção da palhada para o plantio da soja nos meses de outubro. Anteriormente à 2002, a área permanecia em pousio durante os meses de maio a setembro, nascendo na área plantas da família das gramíneas, como o colonião e a braquiária (plantas espontâneas apenas). Na área de ILP, a utilização da cultura do milho e a braquiária semeados simultaneamente (braquiária na entrelinha) ocorreu em um total de 5 vezes (Tabela 2). 
Tabela 2. Sequência de culturas e adubações utilizadas nas áreas avaliadas da Fazenda Vargem Grande da Agropecuária Peeters, em Montividiu, GO.

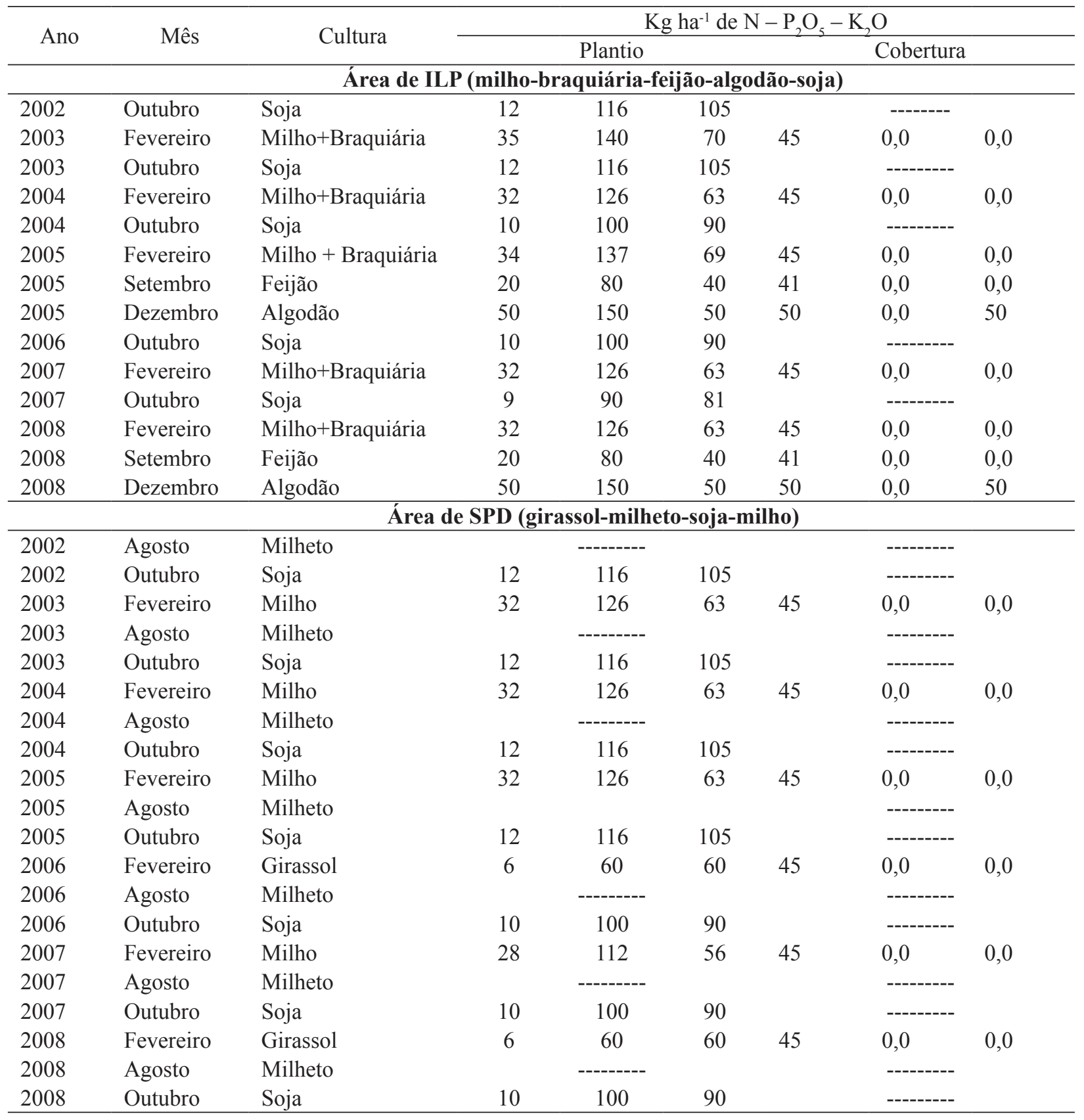

Fonte: Loss (2011).

No período em que foram realizadas as coletas de terra para as avaliações deste trabalho, a área com SPD estava cultivada com soja, e a área sobre ILP cultivada com feijão (Figura 2). Dessa forma, delimitou-se uma área em torno de $600 \mathrm{~m}^{2}$, na qual foram abertas três trincheiras transversais às linhas de semeadura em cada área, para a coleta das amostras, realizadas no final de setembro de 2008. Para cada trincheira foram realizadas amostras compostas de 3 subamostras, nas profundidades de $0,0-10 ; 10-20 ; 20-30$ e $30-40 \mathrm{~cm}$, por sistema avaliado. Após a coleta, as amostras foram secas ao 
ar e peneiradas a $2 \mathrm{~mm}$ de malha.

Foram quantificados o carbono orgânico total (COT), segundo Yeomans e Bremner(1988), carbono orgânico solúvel em água (CSA), pela perda de cor de um complexo de pirofosfato-Mn (III) devido à redução a Mn (II) provocada pelo COT(BARTLETT; ROSS, 1988). Para determinar o CSA, utilizou-se uma amostra de $10 \mathrm{~g}$ de solo de cada tratamento em $20 \mathrm{~mL}$ de $\mathrm{H}_{2} \mathrm{O}$, sendo a suspensão agitada por 15 min, centrifugada e, posteriormente, filtrada em papel umedecido com $\mathrm{H}_{2} \mathrm{O}$. A determinação do CSA foi feita por colorimetria (BARTLETT; ROSS, 1988). O nitrogênio total (NT) foi determinado pelo método de Kjeldahl (BREMNER; MULVANEY, 1982). Com os dados de COT e NT, calculouse a relação $\mathrm{C} / \mathrm{N}$. Na camada de $0,0-20,0 \mathrm{~cm}$, foi feita a caracterização da fertilidade da do solo e a quantificação da granulometria (Tabela 1), segundo Embrapa (1997).

As frações húmicas foram separadas nas frações: ácidos fúlvicos (FAF), ácidos húmicos (FAH) e humina (HUM), sendo utilizada a técnica de solubilidade diferencial estabelecida pela Sociedade Internacional de Substâncias Húmicas (SWIFT, 1996), conforme técnica adaptada e apresentada por Benites, Madari e Machado (2003). Para tal, pesouse uma massa de TFSA igual a 1,0 g, submetendo-se ao contato com $20 \mathrm{~mL}$ de $\mathrm{NaOH} 0,1 \mathrm{~mol} \mathrm{~L}^{-1}$ por 24 horas. A separação entre o extrato alcalino $(\mathrm{EA}=$ C-FAF + C-FAH) e o resíduo (C-HUM) foi feita por centrifugação a $5000 \mathrm{~g}$ por 30 minutos. Seguiu-se mais uma lavagem com a mesma solução anterior, juntando-se o extrato com o anteriormente obtido, resultando em volume final de aproximadamente 40 $\mathrm{mL}$. O resíduo foi retirado dos tubos da centrífuga, acondicionados em placa de petri e secado a $65^{\circ} \mathrm{C}$ (secagem completa). $\mathrm{O} \mathrm{pH}$ do EA foi ajustado a 1,0 $( \pm 0,1)$ com $\mathrm{H}_{2} \mathrm{SO}_{4} 20 \%$, seguido de decantação por 18 horas em geladeira. O precipitado (C-FAH) foi separado da fração solúvel (C-FAF) por filtragem e ambos os volumes aferidos a $50 \mathrm{~mL}$, com água destilada. Posteriormente, quantificou-se o carbono orgânico de cada fração sendo o carbono da FAF (C-FAF), carbono da FAH (C-FAH) e carbono da HUM (C-HUM) segundo Yeomans e Bremner (1988).

Os resultados foram analisados quanto à normalidade e homogeneidade dos dados por meio dos testes de Lilliefors e Cochran e Barttlet, respectivamente. Não foram necessárias o uso de transformações de dados. Posteriormente, foram avaliados como delineamento inteiramente casualizado, com três sistemas de uso do solo tratamentos (SPD, ILP e Cerradão) com 3 repetições cada. Os resultados obtidos foram submetidos à análise de variância com aplicação do teste $\mathrm{F}$ e os valores médios, quando significativos, foram comparados entre si pelo teste de Tukey a $5 \%$.

\section{Resultados e Discussão}

Para os valores de COT na profundidade superficial $(0-10 \mathrm{~cm})$, em área de Cerradão observaram-se os maiores teores no solo (40 g kg${ }^{1}$ ), e verificou-se decréscimo do COT conforme aumentava a profundidade, atingindo valores de $15 \mathrm{~g} \mathrm{~kg}^{-1}$ (Figura 3). O padrão observado devese a maior deposição de matéria orgânica em superfície, que é intensificada devido ao aporte de resíduos vegetais mais lignificados em comparação as plantas cultivadas e, também, devido à ausência de influência antrópica na área de Cerradão. Resultados semelhantes foram encontrados por Sisti et al. (2004); Jantalia et al (2007); Siqueira Neto et al. (2009), Marchão et al. (2009) e Costa Junior et al. (2011), em trabalhos desenvolvidos na mesma região, com áreas de Cerradão sob Latosolo Vermelho. 
Figura 3. Teores de carbono orgânico total (COT), nos diferentes sistemas de uso do solo em Montividiu, GO. (Barras de erros indicam o erro padrão da média, de 3 repetições). Médias seguidas de mesma letra não diferem entre as áreas avaliadas, em cada profundidade, pelo teste Tukey a $5 \%$.

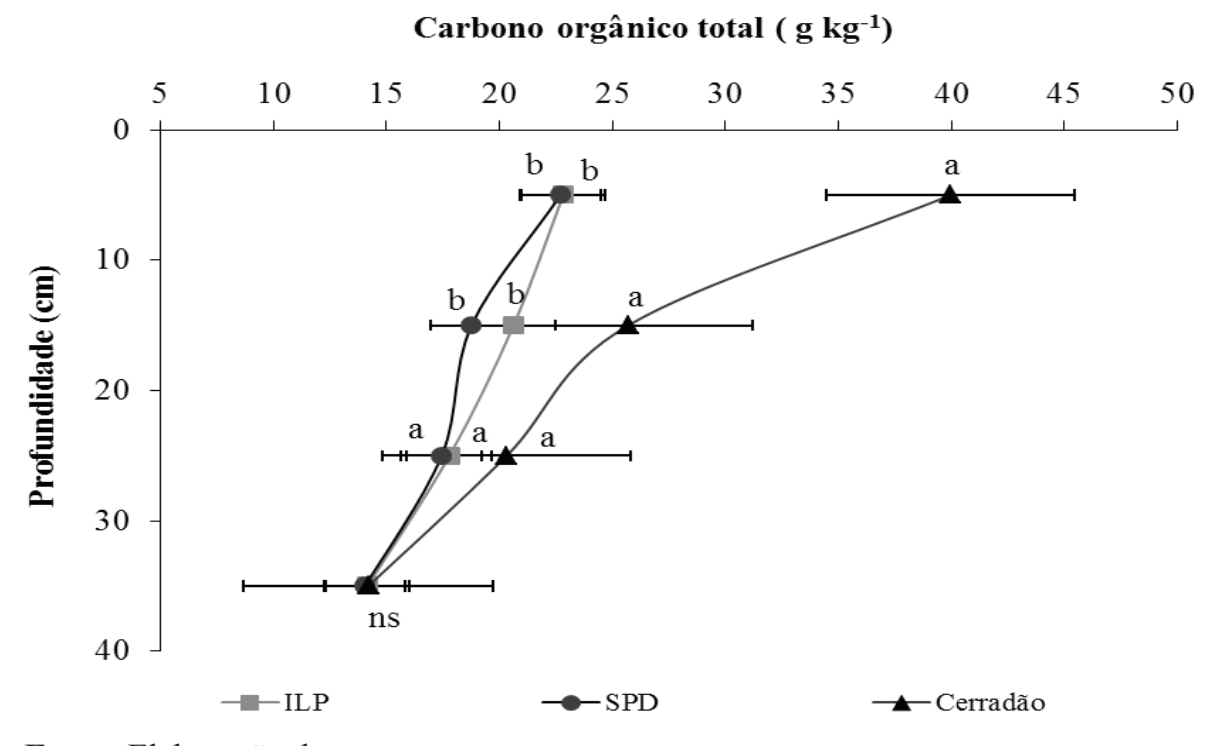

Fonte: Elaboração dos autores.

Os teores de COT encontrados na área de Cerradão apresentaram um decréscimo acentuado em profundidade, sendo este próximo de 36\% (0$10 \mathrm{~cm}$ para $10-20 \mathrm{~cm})$ e $50 \%(0-10 \mathrm{~cm}$ para $20-30$ $\mathrm{cm})$. Menores reduções são observadas quando se comparam os teores de COT entre as áreas cultivadas, sendo na área de SPD verificado um decréscimo variando entre 17 e $23 \%$ e na área de ILP, apenas 10 e 20\% (Figura 3). Estes resultados podem ser devidos a qualidade do material mais lignificado depositado sobre o solo de Cerradão, favorecendo ao acúmulo de COT na camada de 0-10 cm em comparação a camada de $10-20 \mathrm{~cm}$. Nas áreas cultivadas, as menores variações nos teores de COT estão associadas a adubação utilizada (Tabela 2), que favorece direta e/ou indiretamente a atividade microbiana decompositora, acarretando em teores de COT similares entre as áreas e também em profundidade.

Entre as áreas cultivadas não foram observadas diferenças para os teores de COT em nenhuma das profundidades avaliadas. A partir da profundidade de 20-30 cm não foram observadas diferenças estatísticas entre a distribuição dos teores de COT em profundidade para os três sistemas estudados (Figura 3). A ausência de diferenças para os teores de COT em profundidade entre os sistemas avaliados indica que o tempo de cultivo em SPD (17 anos) foi suficiente para que os teores de COT das áreas cultivadas (SPD e ILP) se equiparassem aos da área da condição original do solo (Cerradão). Estes resultados corroboram os encontrados por Siqueira Neto et al. (2009), avaliando os estoques de COT em SPD em Latossolo Vermelho em Rio Verde, GO. Os autores verificaram que a distribuição do carbono em profundidade aumentou como tendência de recuperar os teores originais semelhantes ao do sistema de uso do solo com Cerradão.

Em outro estudo sobre os estoque de COT nas mesmas áreas desse estudo, Loss et al. (2012) verificaram que os estoques de COT não apresentaram diferenças entre as áreas (ILP, SPD e Cerradão) nas camadas de 30-40, 40-50 e 50-60 $\mathrm{cm}$, sendo encontrados maiores estoques de COT na área de ILP $\left(130,95 \mathrm{Mg} \mathrm{ha}^{-1}\right)$ quando comparado com a área de Cerradão $\left(125,34 \mathrm{Mg} \mathrm{ha}^{-1}\right)$ para a camada de $0-60 \mathrm{~cm}$. 
Para os teores de nitrogênio total do solo (N-total) verificaram-se maiores valores na área de Cerradão comparativamente aos sistemas de cultivo do solo (ILP e SPD), independentemente da profundidade avaliada (Figura 4). Estes resultados estão relacionados à ausência da ação antrópica e o constante aporte e qualidade da serapilheira, o que mantém o estado estável nas adições e perdas de COT e N-total (DALAL; MAYER, 1986; URQUIAGA et al., 2005).

Figura 4. Nitrogênio total do solo sob os diferentes sistemas de uso do solo em Montividiu, GO. (Barras de erros indicam o erro padrão da média, de 3 repetições). Médias seguidas de mesma letra não diferem entre as áreas avaliadas, em cada profundidade, pelo teste Tukey a $5 \%$.

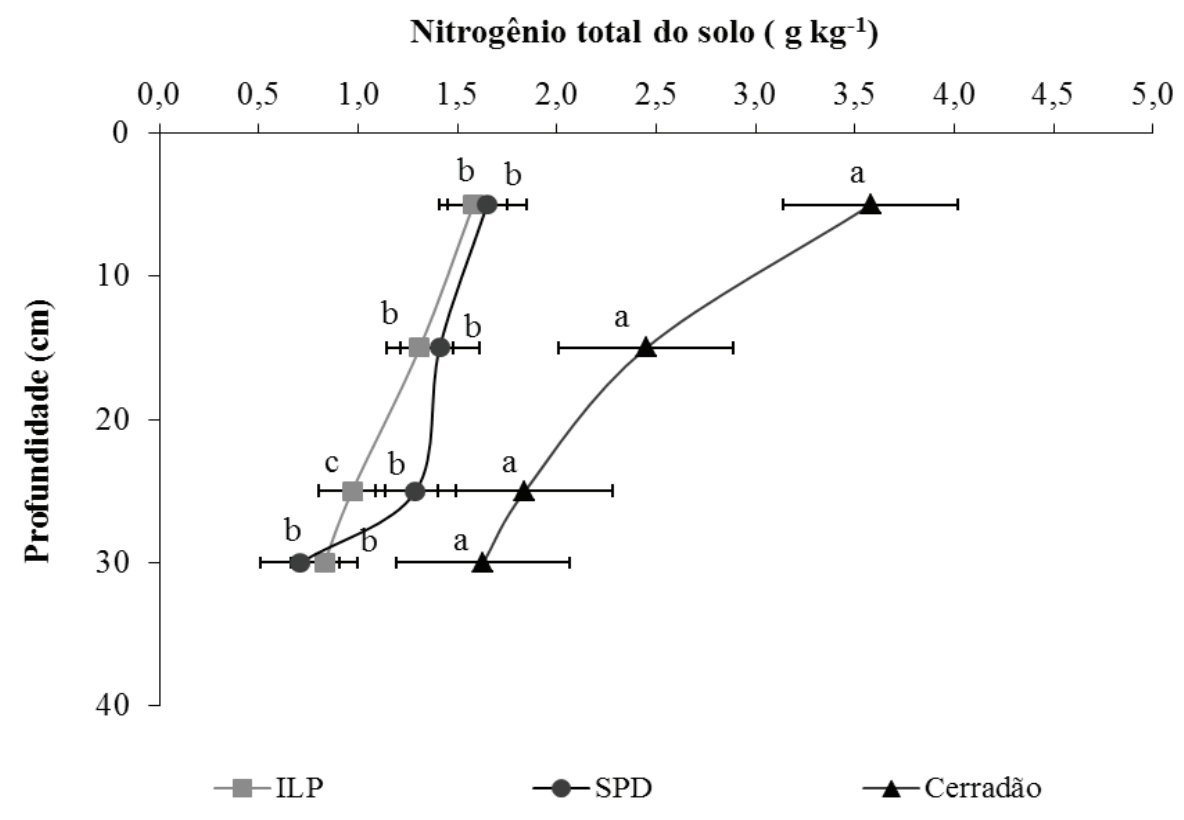

Fonte: Elaboração dos autores.

Entre as áreas cultivadas, verificou-se padrão semelhante ao encontrado para os teores de COT, com ausência de diferenças entre as áreas, à exceção da profundidade de $20-30 \mathrm{~cm}$, onde os maiores teores de N-total foram verificados na área de SPD (Figura 4). Essa relação entre os teores de COT e N-total já foi observada em áreas localizadas em diferentes regiões do Brasil, sob o cultivo de grãos e sob condições de vegetação de Cerrado ou floresta nativa, independente da profundidade do solo (SISTI et al., 2004), corroborando os resultados encontrados neste estudo.

Os maiores teores de N-total na área de SPD (20-30 $\mathrm{cm})$ podem ser devidos ao histórico de uso dessa área. Nesta, a safrinha começou a ser realizada nos últimos cinco anos. Antes disto, após o cultivo da soja, a área permanecia em pousio e parte dos teores de $\mathrm{N}$ estocado no solo são provenientes da decomposição do sistema radicular da cultura da soja, disponibilizado somente após a morte da planta (MAYER et al., 2003; KHAN et al., 2003). Segundo estes autores, utilizando a técnica de marcação do isótopo ${ }^{15} \mathrm{~N}$ em caules de plantas de soja, cerca de 15 a $23 \%$ do total de $\mathrm{N}$ acumulado na planta correspondem ao $\mathrm{N}$ oriundo do sistema radicular, o qual não é removido das áreas plantadas.

Em outro estudo utilizando o isótopo ${ }^{15} \mathrm{~N}$ para quantificação do $\mathrm{N}$ derivado das raízes da soja, Araújo et al. (2004) verificaram que $20 \%$ do $\mathrm{N}$ acumulado no solo era derivado do sistema 
radicular da soja, sendo observado na camada de 0-20 $\mathrm{cm}$ um acúmulo de $58 \mathrm{~kg} \mathrm{ha}^{-1}$ de $\mathrm{N}$. Isso pode justificar os maiores teores de $\mathrm{N}$ no solo na área de SPD, pois na safrinha não havia culturas agrícolas, sendo ocupada por plantas da família das gramíneas tais como capim colonião (Panicum maximum) e braquiária ( $U$. ruziziensis), ambas $\mathrm{C}_{4}$. Essas gramíneas mais a utilização do milheto como planta de cobertura nos últimos cinco anos, associadas a adubação nitrogenada (Tabela 2), podem aportar mais $\mathrm{N}$ ao solo por meio da ciclagem de nutrientes e morte do sistema radicular. Em contra-partida, no sistema de ILP, o cultivo mais intensivo do solo (milho+braquiária e pastejo de bovinos) pode levar a maior extração de nutrientes nas áreas sob ILP, acarretando em menores valores de N-total (20-30 $\mathrm{cm}$ ) e/ou valores iguais ao SPD, se comparado com a maior utilização de adubos nitrogenados (Tabela 2).

Além do $\mathrm{N}$ proveniente da decomposição do sistema radicular da soja, soma-se o efeito positivo da palhada de milheto, que por meio de seu sistema radicular, consegue adicionar carbono ao solo, assim como a braquiária. Segundo Urquiaga et al. (2005), em estudo sobre sistemas agrícolas para seqüestro de carbono no solo em ambientes tropicais e subtropicais, o conteúdo de $\mathrm{N}$ orgânico do solo não poderá ser aumentado sem que haja acréscimo correspondente nos teores de carbono e vice-versa. Por esta razão, na área de SPD, observaram-se teores de N-total em profundidades maiores que os encontrados na área com ILP.
Os valores da relação $\mathrm{C} / \mathrm{N}$ variaram de 8,70 a 11,16 na área de Cerradão; de 13,30 a 19,77 na de SPD, e, para a área de ILP, os valores variaram de 14,44 a 18,32, em função da profundidade (Figura 5). Os menores valores de $\mathrm{C} / \mathrm{N}$ foram observados na área de Cerradão e os maiores, na área de ILP, com exceção a camada de 30-40 cm, onde o SPD superou o sistema de ILP. Na área de Cerradão, a menor relação $\mathrm{C} / \mathrm{N}$ está associada aos maiores teores totais de C (Figura 3) e N (Figura 4), assim como relatado por Loss et al. (2011), avaliando a relação $\mathrm{C} / \mathrm{N}$ de agregados do solo de Cerradão e comparado a sistemas de uso do solo em Goiás.

No Cerradão, o sistema já está estável, com a relação $\mathrm{C} / \mathrm{N}$ tendendo a ser mais próxima da biomassa microbiana, com valores de $\mathrm{C}$ e $\mathrm{N}$ variando em proporções mais estáveis (LOSS, 2011). Padrão contrário foi observado nas áreas cultivadas, onde há maiores estoques de $\mathrm{C}$ para ILP e estoques semelhantes de N entre ILP e SPD, para a camada de 0-100 cm (LOSS et al., 2012), propiciando maiores valores de $\mathrm{C} / \mathrm{N}$ na área de ILP em comparação a área de SPD, para 10-20 e 20$30 \mathrm{~cm}$ (Figura 5). Além disso, na área de ILP, os maiores valores de $\mathrm{C} / \mathrm{N}$ podem ser decorrentes do uso da braquiária e do milho. A grande vantagem da palhada de braquiária é a relação $\mathrm{C} / \mathrm{N}$ elevada, que mantém o solo coberto até o fechamento da entrelinha das culturas, resultando ao final do ciclo da soja, por exemplo, em $4.000 \mathrm{~kg} \mathrm{ha}^{-1}$ de palhada (CRUSCIOL; BORGHI, 2007). 
Figura 5. Variação dos valores da relação $\mathrm{C} / \mathrm{N}$ (padronizar com $\mathrm{C} / \mathrm{NOK}$ ) no solo sob os diferentes sistemas de uso do solo em Montividiu - GO. (Barras de erros indicam o erro padrão da média, de 3 repetições). Médias seguidas de mesma letra não diferem entre as áreas avaliadas, em cada profundidade, pelo teste Tukey a 5\%.

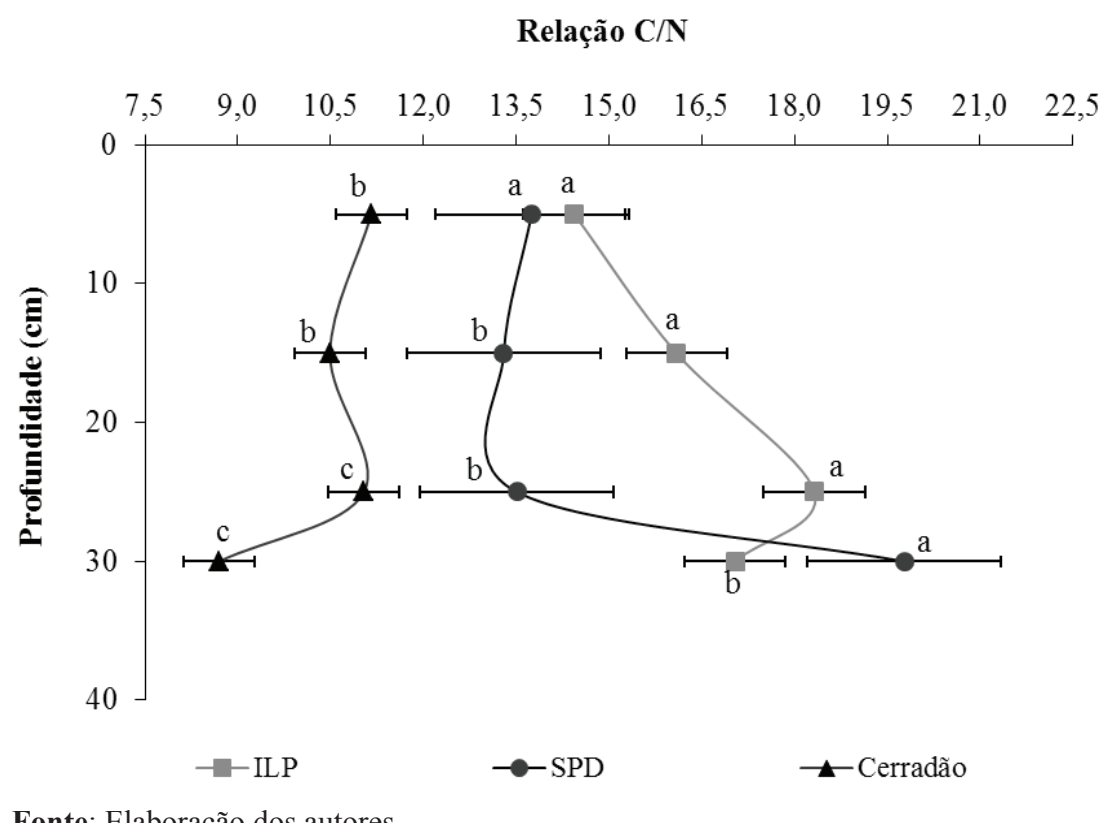

$\mathrm{Na}$ profundidade de $30-40 \mathrm{~cm}$, os maiores valores de $\mathrm{C} / \mathrm{N}$ na área de $\mathrm{SPD}$ podem estar associados ao efeito do sistema radicular do milheto em profundidade, utilizado na rotação de culturas, e também a menor proporção de $\mathrm{N}$ verificada na área de SPD quando comparada à ILP, apesar de não ter apresentado diferenças (Figura 4).

A análise dos dados do CSA evidenciou diferenças significativas entre todos os sistemas de uso do solo e as profundidades de amostragem (Tabela 3), diferentemente do COT que não apresentou diferenças entre os sistemas de cultivo para as profundidades avaliadas (Figura 3). Este resultado permite inferir que o CSA foi mais eficiente em identificar diferenças relacionadas a qualidade do $\mathrm{C}$ e das formas de $\mathrm{C}$ no solo promovidas pelos sistemas de uso do solo avaliados (SPD, ILP e Cerradão) quando comparado ao COT, para as condições edafoclimáticas do presente estudo.

Tabela 3. Teores de carbono solúvel em água (CSA, $\left.\mathrm{mg} \mathrm{kg}^{-1}\right)$ nos diferentes sistemas de uso do solo e profundidades, em Montividiu, GO.

\begin{tabular}{|c|c|c|c|c|c|}
\hline \multirow{2}{*}{$\begin{array}{l}\text { Sistemas } \\
\text { avaliados }\end{array}$} & \multicolumn{4}{|c|}{ Profundidade $(\mathrm{cm})$} & \multirow{2}{*}{ CV $(\%)$} \\
\hline & 0-10 & $10-20$ & $20-30$ & $30-40$ & \\
\hline ILP & $5,20 \mathrm{Ba}$ & $2,17 \mathrm{Cb}$ & $1,62 \mathrm{Bc}$ & $1,54 \mathrm{Bc}$ & 13,06 \\
\hline SPD & $2,10 \mathrm{Cc}$ & $6,05 \mathrm{Ab}$ & $9,84 \mathrm{Aa}$ & $5,97 \mathrm{Ab}$ & 10,96 \\
\hline Cerradão & 8,89 $\mathrm{Aa}$ & $4,46 \mathrm{Bb}$ & $1,43 \mathrm{Bc}$ & $1,62 \mathrm{Bc}$ & 11,58 \\
\hline CV (\%) & 10,14 & 13,24 & 12,43 & 11,78 & - \\
\hline
\end{tabular}

Médias seguidas de letras maiúsculas iguais nas colunas e minúsculas iguais nas linhas, em cada sistema, não diferem entre si pelo teste de Tukey a 5\% de probabilidade. $\mathrm{CV}=$ coeficiente de variação.

Fonte: Elaboração dos autores. 
A Tabela 3 mostra ampla variação dos teores de CSA e que a distribuição desses teores foi influenciada pela profundidade e pelo sistema de uso do solo. Entre os sistemas avaliados, a área de Cerradão apresentou os maiores teores de CSA na profundidade de $0-10 \mathrm{~cm}$, seguidos pela área de ILP e os menores valores foram verificados na área de SPD. Para as demais profundidades, a área com SPD apresentou os maiores teores de CSA, sendo verificados valores iguais entre as demais áreas, com exceção à profundidade de 10-20 cm, onde o sistema de ILP apresentou os menores valores de CSA (Tabela 3).

Os maiores teores de CSA na área de Cerradão (0$10 \mathrm{~cm}$ ) são decorrentes dos maiores teores de COT (Figura 3), que por sua vez foram proporcionados pelo aporte da serapilheira nesta área. Segundo Kalbitz et al. (2000), as fontes potenciais de CSA são a serapilheira e os compartimentos da MOS, como, por exemplo, a biomassa microbiana e as raízes. Entre as áreas cultivadas, os maiores teores de CSA na área de ILP $(0-10 \mathrm{~cm})$ podem ser decorrentes da ação conjunta dos sistemas radiculares do milho + braquiária em comparação ao milheto na área de SPD.

Em profundidade, os menores teores de CSA na área de ILP podem ser devidos aos maiores teores de Ca quando comparado com a área de SPD (Tabela 1). Em solos corrigidos quimicamente há maior concentração de carbono na solução, que por sua vez está associado à maior solubilidade da MOS, ao aumento da atividade microbiana e de produção de compostos mais solúveis, além da substituição de CSA adsorvido à fase sólida por ânions mobilizados (troca de ligantes) após a adição de calcário no solo (ERICH; TRUSTY, 1997; GUGGENBERGER; ZECH; SCHULTEN, 1994; KALBITZ et al., 2000). Por outro lado, o consumo de carbono dissolvido em água pela microbiota (ANDERSSON, 1999) e a floculação ou adsorção de carbono em pontes de cátions formadas em razão do alto teor de Ca no solo podem contribuir para as perdas de carbono via solução em solos onde a acidez é corrigida. Em contrapartida, em solos minerais não corrigidos, as baixas concentrações de CSA estão mais relacionadas aos fenômenos de adsorção do que aos fenômenos de biodegradação (MIRANDA et al., 2006), conforme verificado na área de Cerradão, em profundidade.

Outro fator que também contribui para os menores teores de CSA nas áreas de ILP e Cerradão em profundidade são os maiores teores de C-FAF (Tabela 4) quando comparado com a área de SPD. Os ácidos fúlvicos são moléculas alifáticas que apresentam maior quantidade de radicais carboxílicos do que outros grupos de substâncias húmicas (C-FAH e C-HUM), além de ser mais reativas no solo, mostram maior solubilidade e menor massa molar, podendo por conseguinte, ser solvatadas e perdidas mais facilmente por lixiviação (STEVENSON, 1994).

Para verificar este padrão, Ribas et al. (2008) realizaram um ensaio de lixiviação de carbono em colunas preenchidas com solo de diferentes sistemas (mata, cana-de-açúcar e pastagem) em Campos dos Goytacazes, RJ, e submetidas (simulado) a diferentes regimes pluviométricos, sendo 250, 500, 750 e $1000 \mathrm{~mm}$. Os solos sob pastagem apresentaram maior concentração de carbono lixiviado (valores superores a $100 \mathrm{mg} . \mathrm{L}^{-1}$ de $\mathrm{C}$, sendo observado para cana e pastagem, valores em torno de 40 mg. $\mathrm{L}^{-1}$ de C) de acordo com os diferentes regimes pluviométricos (artificiais) submetidos. Segundo Ribas et al. (2008), os maiores valores de carbono lixiviados na área de pastagem são decorrentes das maiores concentrações de C-FAF $\left(2,38 \mathrm{~g} \mathrm{~kg}^{-1}\right)$ em detrimento as áreas de cana e mata $(1,39$ e $1,19 \mathrm{~g}$ $\mathrm{kg}^{-1}$, respectivamente). Portanto, sistemas onde tem-se formas de carbono mais solúveis e menos humificadas apresentam mais carbono prontamente lixiviável.

Os sitemas de uso do solo apresentaram padrão semelhante para ILP e Cerradão entre as profundidades avaliadas. Os valores de CSA foram diminuindo de acordo com a profundidade para 
ILP e Cerradão .Para a área de SPD, verificou-se padrão contrário a esse, com maiores valores de CSA na profundidade de 20-30 cm (Tabela 3). Estes resultados podem ser devido aos maiores teores de C-FAH na área de SPD em profundidade quando comparados com as demais áreas. O C-FAH é mais estável e apresnta maiores teores de $\mathrm{N}$ quando comparado ao C-FAF (STEVENSON, 1994), por isso tem-se mais CSA no SPD quando comparado ao ILP e Cerradão, que apresentaram maiores teores de C-FAF, para a mesma profundidade (Tabela 3), ambos decrescendo conforme aumentava a profundidade.
As frações húmicas da MOS mostraram diferenças significativas entre os sistemas de uso de solo, inclusive para as profundidades amostradas (Tabela 4), diferentemente dos resultados de COT, o qual não promoveu diferenças significativas entre os sistemas de cultivo avaliados em nenhuma das profundidades (Figura 3). Este resultado mostra que o teor de carbono das frações húmicas foi mais eficiente em identificar diferenças provenientes dos sistemas de uso do solo avaliados quando comparado ao COT, assim como se observou para o CSA nas condições edafoclimáticas do presente estudo.

Tabela 4. Carbono das frações húmicas da MOS nos diferentes sistemas de uso do solo e profundidades, em Montividiu- GO.

\begin{tabular}{|c|c|c|c|c|c|}
\hline \multirow{3}{*}{ Sistemas avaliados } & \multicolumn{4}{|c|}{ C-HUM ( g kg-1) $^{-1}$} & \multirow{3}{*}{ CV $(\%)$} \\
\hline & \multicolumn{4}{|c|}{ Profundidade $(\mathrm{cm})$} & \\
\hline & 0-10 & $10-20$ & $20-30$ & $30-40$ & \\
\hline ILP & $25,95 \mathrm{Ba}$ & $19,55 \mathrm{Bb}$ & $14,96 \mathrm{Bc}$ & 9,77 Bd & 6,44 \\
\hline SPD & $25,93 \mathrm{Ba}$ & $17,84 \mathrm{Cb}$ & $10,71 \mathrm{Cc}$ & $6,86 \mathrm{Cd}$ & 3,95 \\
\hline Cerradão & $30,14 \mathrm{Aa}$ & $21,22 \mathrm{Ab}$ & $19,66 \mathrm{Ab}$ & $15,09 \mathrm{Ac}$ & 3,10 \\
\hline CV $(\%)$ & 3,21 & 2,68 & 4,67 & 5,41 & - \\
\hline \multirow{3}{*}{ Sistemas avaliados } & \multicolumn{4}{|c|}{ C-FAH ( ( kg $\left.^{-1}\right)$} & \multirow{3}{*}{ CV $(\%)$} \\
\hline & & Profun & e (cm) & & \\
\hline & 0-10 & $10-20$ & $20-30$ & $30-40$ & \\
\hline ILP & $3,83 \mathrm{Ba}$ & $2,85 \mathrm{Ab}$ & $2,10 \mathrm{Bc}$ & $1,69 \mathrm{Bd}$ & 3,15 \\
\hline SPD & $3,87 \mathrm{Ba}$ & $2,30 \mathrm{Bd}$ & $2,70 \mathrm{Ac}$ & $3,14 \mathrm{Ab}$ & 4,22 \\
\hline Cerradão & 4,50 Aa & $1,55 \mathrm{Cb}$ & $1,28 \mathrm{Cc}$ & $1,01 \mathrm{Cd}$ & 2,46 \\
\hline CV $(\%)$ & 2,55 & 4,72 & 4,51 & 3,12 & - \\
\hline \multirow{3}{*}{ Sistemas avaliados } & \multicolumn{4}{|c|}{ C-FAF $\left(\mathrm{g} \mathrm{kg}^{-1}\right)$} & \multirow{3}{*}{ CV (\%) } \\
\hline & \multicolumn{4}{|c|}{ Profundidade (cm) } & \\
\hline & 0-10 & $10-20$ & 20-30 & $30-40$ & \\
\hline ILP & $7,12 \mathrm{Aa}$ & $6,39 \mathrm{Ab}$ & $5,73 \mathrm{Ac}$ & $4,22 \mathrm{Ad}$ & 3,86 \\
\hline SPD & $6,12 \mathrm{Ca}$ & $5,02 \mathrm{Bb}$ & $4,19 \mathrm{Cc}$ & $3,86 \mathrm{Bd}$ & 2,28 \\
\hline Cerradão & $6,23 \mathrm{Ba}$ & $4,61 \mathrm{Bc}$ & 4,99 Bb & 4,22 Ad & 2,56 \\
\hline CV $(\%)$ & 2,44 & 4,65 & 2,56 & 2,76 & - \\
\hline
\end{tabular}

Médias seguidas de letras maiúsculas iguais nas colunas e minúsculas iguais nas linhas, em cada sistema, não diferem entre si pelo teste de Tukey a $5 \%$ de probabilidade. $\mathrm{CV}=$ coeficiente de variação.

Fonte: Elaboração dos autores.

O maior valor de C-HUM foi encontrado na área de Cerradão e o menor em área de SPD, para todas as profundidades avaliadas, com exceção da profundidade de 0-10 cm, na qual as áreas cultivadas não diferiram entre si (Tabela 4). Na área de Cerradão, os maiores valores de C-HUM podem ser justificados pelo maior aporte de serapilheira e ausência de influência antrópica nesta área, 
apresentando o mesmo padrão do COT. Entre as áreas cultivadas, no sistema de ILP, os maiores teores de C-HUM provavelmente são devidos ao aporte vegetal de maior relação $\mathrm{C} / \mathrm{N}$ (milho+braquiária). Dessa forma, há menor velocidade de decomposição dos resíduos adicionados ao solo na área de ILP, propiciando a formação de substâncias mais estáveis, como a humina. Em profundidade, todos os sistemas avaliados apresentaram o mesmo padrão, com valores de C-HUM decrescendo com o aumento da profundidade.

Os maiores teores de C-FAH foram verificados na área de Cerradão na profundidade superficial (0-10 cm), e os menores valores para esta área ocorreram nas demais profundidades (Tabela 3). Este padrão é decorrente do maior aporte de material vegetal (serapilheira) em superfície (0$10 \mathrm{~cm}$ ), associado a maior atividade microbiana. Já em profundidade tem-se a menor contribuição do aporte vegetal e, consequentemente, menor atividade microbiana e menor formação de ácidos húmicos. Entre as áreas cultivadas, destaca-se a área de ILP com maiores teores de C-FAH na profundidade de $10-20 \mathrm{~cm}$ e maiores teores de C-FAH para a área de SPD para as profundidades subsequentes. Estes resultados pode ser devido ao efeito da braquiária no sistema de ILP e do milheto, em profundidade, na área de SPD.

Os resíduos vegetais (palhada e sistema radicular) das gramíneas (braquiária e milheto) acarretam em aumento dos ácidos húmicos no solo por possuírem maior conteúdo de lignina (PRIMAVESI, 1982), ocasionando em decomposição mais branda por meio da biota do solo, assim favorecendo a formação dos ácidos húmicos. Resultados semelhantes são relatados por Pereira et al. (2012), avaliando os estoques de carbono das frações húmicas em Latossolo Veremlho em SPD no Cerrado, Uberaba, MG. Os autores encontraram maiores estoques de C-FAH na camada superficial $(0-5 \mathrm{~cm})$ do solo sob cobertura de braquiária e em profundidade (0-20 $\mathrm{cm})$, sob cobertura de milheto.
A área manejada com ILP e a de Cerradão apresentaram decréscimo dos teores de C-FAH com o aumento da profundidade e resultado contrário foi verificado em área sob SPD, provavelmente pelo uso do milheto. Esta gramínea por meio de seu sistema radicular bem desenvolvido, atinge mais de 2,0 $\mathrm{m}$ de profundidade do solo (ALVARENGA et al., 2001), e a partir da decomposição do sistema radicular, ocorre incorporação de carbono em profundidade (FOY, 1997). E, este carbono, proveniente de resíduos vegetais de maior relação $\mathrm{C} / \mathrm{N}$ e mais lignificado, está aumentando os teores de C-FAH em profundidade, em maior proporção, quando comparado com a área de ILP.

Entre os sistemas de manejo avaliado, o C-FAF encontra-se distribuído mais uniformemente em profundidade quando comparado com o C-FAH (Tabela 3). O C-FAF apresentou maiores teores para a área de ILP em todas as profundidades avaliadas, exceto, na última camada $(30-40 \mathrm{~cm})$, não sendo observadas diferenças significativas entre ILP e Cerradão. De maneira geral, os menores teores de C-FAF foram encontrados para a área de SPD. Estes resultados podem ser decorrentes das palhadas utilizadas nas áreas, sendo a de milheto no SPD e de braquiária no ILP. Para a região do Cerrado, em Uberaba, a palhada do milheto apresenta, em média relação $\mathrm{C} / \mathrm{N}$ mais elevada que a palhada da braquiária (TORRES et al., 2005). Com maior taxa de decomposição dos resíduos vegetais, associadas ao período de início das chuvas (Figura 1), pode-se ter a formação dos ácidos fúlvicos em detrimento aos ácidos húmicos. Este padrão foi observado nas áreas em sistema de ILP, em profundidade, onde se verificaram maiores teores de C-FAF quando comparado a área de SPD (Tabela 4). Em contrapartida, para o C-FAH, verificaram-se maiores teores na área de SPD, em profundidade, onde temse a palhada do milheto, com maior relação $\mathrm{C} / \mathrm{N}$.

Estes resultados são corroborados por Rossi et al. (2011), avaliando a quantificação do carbono das frações húmicas em diferentes sistemas de uso do 
solo em Montividiu, GO. Estes autores verificaram que o SPD com palhada da braquiária apresentou maiores teores de C-FAF e no SPD com palhada de milheto, maiores teores de C-FAH, ambos avaliados em condições edafoclimáticas semelhantes ao deste estudo (Cerrado de Montividiu, GO, no mês de outubro de 2007).

\section{Conclusões}

Os sistemas de ILP e SPD não promoveram alterações no solo significativas para serem identificadas através dosteores de COT e N-Total, exceto para $\mathrm{N}$ na camada de $20-30 \mathrm{~cm}$.

O sistema de ILP favorece a formação do C-HUM em comparação ao SPD.

O sistema de ILP acarreta em menores teores de CSA e maiores de C-FAF quando comparado com o SPD, que apresenta maiores teores de CSA e C-FAH.

Os teores de CSA e de C das frações húmicas foram mais eficientes para identificar alterações promovidas no solo decorrentes aos sistemas avaliados (SPD, ILP e Cerradão).

\section{Agradecimentos}

À Fundação Agrisus e CAPES pelo apoio financeiro. Ao Curso de Pós-Graduação em Agronomia - Ciência do Solo da UFRRJ pelo auxílio prestado e ao Instituto Federal de Educação Tecnológica Goiano pelo auxílio na coleta das amostras de terra.

\section{Referências}

ALVARENGA, R. C.; CABEZAS, W. A. L.; CRUZ, J. C.; SANTANA, D. P. Plantas de cobertura de solo para sistema plantio direto. Informe Agropecuário, Belo Horizonte, v. 22, n. 208, p. 25-36, 2001

ANDERSSON, S. Influence of liming substances and temperature on microbial activity and leaching of soil organic matter in coniferous forest ecosystems. Acta
Universitatis Agriculturae Sueciae Agraria, Alnarp, v. 116, n. 1, p. 1-68, 1999.

ARAÚJO, E. S.; MEDEIRO, A. F. A.; DIAS, F. C.; URQUIAGA, S.; BODDEY, R. M.; ALVES, B. J. R. Quantificação do $\mathrm{N}$ do solo derivado das raízes da soja utilizando o isótopo 15N. Revista de Ciências da Vida, Seropédica, v. 24, n. 1, p. 7-12, 2004.

ASHAGRIE, Y.; ZECH, W.; GUGGENBERGER, G.; MAMO, T. Soil aggregation, and total and particulate organic matter following conversion of native forests to continuous cultivation in Ethiopia. Soil \& Tillage Research, Amsterdam, v. 94, n. 1, p. 101-108, 2007.

BARTLETT, R. J.; ROSS, D. N. Colorimetric determination of oxidizable carbon in acid soil solutions. Soil Science Society of America Journal, Madison, v. 52, n. 2, p. 1191-1192, 1988.

BENITES, V. M.; MADARI, B.; MACHADO, P. L. O. A. Extração e fracionamento quantitativo de substâncias húmicas do solo: um procedimento simplificado de baixo custo. Rio de Janeiro: Embrapa Solos, 2003. 7 p. (Embrapa solos. Comunicado técnico, 16).

BERNOUX, M.; CERRI, C. C.; CERRI, C. E. P.; SIQUEIRA NETO, M.; METAY, A.; PERRIN, A.; SCOPEL, E.; BLAVET, D.; PICCOLO, M. C.PICCOLO, M. C. Influence du semis direct avec couverture végétale sur la séquestration du carbone et érosion au Brésil. Bulletin Du Reseau Erosion, Montpellier, v. 23, n. 1, p. 323-337, 2004.

BLANCHART, E.; BERNOUX, M.; SARDA, X.; SIQUEIRA NETO, M.; CERRI, C. C.; PICCOLO, M. C.; DOUZET, J.; SCOPEL, E.; FELLER, C. Effect of direct seeding mulch-based systems on soil carbon storage and macrofauna in Central Brazil. Agriculturae Conspectus Scientificus, Zagreb, v. 72, n. 1, p. 81-87, 2007.

BREMNER, J. M.; MULVANEY, C. S. Total nitrogen. In: PAGE, A. L. (Ed.). Methods of soil analysis. Madison: American Society of Agronomy, 1982. p. 595-624.

BUSTAMANTE, M. M. C.; MEDINA, E.; ASNER, G. P.; NARDOTO, G. B.; GARCIAMONTIEL, D. C. Nitrogen cycling in tropical and temperate savannas. Biogeochemistry, Corvallis, v. 79, n. 1-2, p. 209-237. 2006.

CARVALHO, J. L. N.; RAUCCI, G. S.; CERRI, C. E. P.; BERNOUX, M.; FEIGL, B. J.; WRUCK, F. J.; CERRI, C. C. Impact of pasture, agriculture and crop-livestock systems on soil C stocks in Brazil. Soil Tillage Research, Amisterdan, v. 110, n. 1, p. 175-186, 2010.

COSTA JUNIOR, C.; PICCOLO, M. C.; SIQUEIRA NETO, M.; CAMARGO, P. B.; CERRI, C. C.; BERNOUX, M. Carbono total e $13 \mathrm{C}$ em agregados do 
solo sob vegetação nativa e pastagem no bioma cerrado. Revista Brasileira de Ciência do Solo, Viçosa, v. 35, n. 5, p. 1241-1252, 2011.

CUNHA, T. J. F.; MACEDO, J. R.; RIBEIRO, L. P.; PALMIERI, F.; FREITAS, P. L.; AGUIAR, A. C. Impacto do manejo convencional sobre propriedades físicas e substâncias húmicas de solos sob cerrado. Ciência Rural, Santa Maria, v. 1, n. 1, p. 27-36, 2001.

CRUSCIOL, C. A. C.; BORGHI, E. Consórcio de milho com braquiária: produção de forragem e palhada para o plantio direto. Revista Plantio Direto, Passo Fundo, ed. 100, p. 6, 2007.

DALAL, R. C.; MAYER, R. J. Long-term trends in fertility of soils under continuous cultivation and cereal cropping in southern Queensland. I. Overall changes in soil properties and trends in winter cereal yields. Australian Journal of Soil Research, Collingwood, v. 24, n. 2, p. 265-279, 1986.

EMPRESA BRASILEIRA DE PESQUISA AGROPECUÁRIA - EMBRAPA. Manual de métodos de análise de solo. 2. ed. Rio de Janeiro: CNPS, 1997.

ERICH, M. S.; TRUSTY, G. M. Chemical characterization of dissolved organic matter released by limed and unlimed forest soil horizons. Canadian Journal Soil Science, Ottawa, v. 77, n. 3, p. 405-413, 1997.

FONTANA, A.; PEREIRA, M. G.; LOSS, A.; CUNHA, T. J. F.; SALTON, J. C. Atributos de fertilidade e frações húmicas de um Latossolo Vermelho no Cerrado. Pesquisa Agropecuária Brasileira, Brasilia, v. 41, n. 5, p. 847-853. 2006.

FONTANA, A.; PEREIRA, M. G.; LOSS, A.; CUNHA, T. J. F.; SALTON, J. C. Fósforo remanescente e correlação com as frações da matéria orgânica em um Latossolo Vermelho 108 distroférrico sob diferentes sucessões de cultura em plantio direto. Revista Brasileira de Agrociência, Pelotas, v. 14, n. 1, p. 159-164, 2008.

FONTANA, A.; BRITO, R. J.; PEREIRA, M. G.; LOSS, A.; BENITES, V. M. Caracterização de susbtâncias húmicas da camada superficial do solo sob diferentes coberturas vegetais. Magistra, Cruz das Almas, v. 22, n. 1, p. 49-56, 2010.

FONTANA, A.; PEREIRA, M. G.; ANJOS, L. H. C.; BENITES, V. M. Classificação de horizontes diagnósticos em níveis inferiores com base nas frações húmicas. Revista Brasileira de Ciência do Solo, Viçosa, v. 35, n. 2, p. 313-324, 2011.

FOY, C. D. Tailoring plants to fit problem soil - progress and problems for future research. In: MONIZ, A. C.; FURLANI, A. M.; SHAFFERT, R. E. (Ed.). Plant soil interactions at low $\mathrm{pH}$ : sustainable agriculture and forestry production. Campinas, Sociedade Brasileira de Ciência do Solo, 1997. p. 55-57.

GUGGENBERGER, G.; ZECH, W.; SCHULTEN, H. R. Formation and mobilization pathways of dissolved organic matter: evidence from chemical structural studies of organic matter fractions in acid forest floor solutions. Organic Geochemistry, Bristol, v. 21, n. 1, p. 51-56, 1994.

JANTALIA, C. P.; RESCK, D. V. S.; ALVES, B. J. R.; ZOTARELLI, L.; URQUIAGA, S.; BODDEY, R. M. Tillage effect on $\mathrm{C}$ stocks of a clayey oxisol under a soybean-based crop rotation in the Brazilian Cerrado. Soil Tillage Research, Amisterdan, v. 95, n. 1-2, p. 97109, 2007.

KALBITZ, K.; SOLINGER, S.; PARK, J. H.; MICHALZIK, B.; MATZNER, E. Controls on the dynamics of dissolved organic matter in soils: A review. Soil Science, Baltimore, v. 165, n. 4, p. 277-304, 2000.

LAL, R. Soil carbon sequestration in Latin America. In: LAL, R.; CERRI, C. C.; BERNOUX, M.; ETCHEVES, J.; CERRI, E. Carbon sequestration in soils of Latin America. New York: Food Products Press, 2006. p. 4964.

LOSS, A.; PEREIRA, M. G.; SCHULTZ, N.; ANJOS, L. H. C.; SILVA, E. M. R. Quantificação do carbono das substâncias húmicas em diferentes sistemas de uso do solo e épocas de avaliação. Bragantia, Campinas, v. 69, n. 4, p. 913-922, 2010.

LOSS, A. Dinâmica da matéria orgânica, fertilidade e agregação do solo em áreas sob diferentes sistemas de uso no cerrado goiano. 2011. Tese (Doutorado em Agronomia/Ciência do Solo) - Universidade Federal Rural do Rio de Janeiro, Seropédica.

LOSS, A.; PEREIRA, M. G.; ANJOS, L. H. C.; GIACOMO, S. G.; PERIN, A. Agregação, carbono e nitrogênio em agregados do solo sob plantio direto com integração lavoura-pecuária. Pesquisa Agropecuária Brasileira, Brasília, v. 46, n. 10, p. 1269-1276, 2011.

LOSS, A.; PEREIRA, M. G.; PERIN, A.; BEUTLER, S. J.; ANJOS, L. H. C. Carbon, nitrogen and natural abundance of ${ }^{13} \mathrm{C}$ e ${ }^{15} \mathrm{~N}$ of light-fraction organic matter under no-tillage system and crop-livestock integration in the Cerrado. Acta Scientiarum. Agronomy, Maringá, v. 34, n. 4, p. 468-474. 2012.

KHAN, F. D.; PEOPLES, M. B.; SCHWENKE, G. D.; FELTTON, W. L.; CHEN, D.; HERRIDGE, D. F. Effects of below-ground nitrogen on $\mathrm{N}$ balances of field-grown fababean, chickpea, and barley. Australian Journal Agriculture Research. Collingwood, v. 54, n. 4, p. 333340, 2003. 
MACEDO, M. C. M. Integração lavoura e pecuária: o estado da arte e inovações tecnológicas. Revista Brasileira de Zootecnia, Viçosa, v. 38, p. 133-146, 2009. Especial.

MARCHÃO, R.; BECQUER, T.; BRUNET, D.; BALBINO, L.; VILELA, L.; BROSSARD, M. Carbon and nitrogen stocks in a Brazilian clayey Oxisol: 13-year effects of integrated crop livestock management systems. Soil Tillage Research, Amisterdan, v. 103, n. 2, p. 442450, 2009.

MAYER, J.;BUEGGER, F.; JENSEN, E. S.; SCHLOTER, M.; HEB, J. Estimating $\mathrm{N}$ rhizodeposithion of grain legumes using a $15 \mathrm{~N}$ in situ stem labeling method. Soil Biology and Biochemistry, Brisbane, v. 35, n. 1, p. 21-28, 2003.

MENDONZA, H. N. S.; LIMA, E.; ANJOS, L. H. C.; SILVA, L. A.; ANTUNES, M. V. A. M. Propriedades químicas e biológicas de solos de Tabuleiro cultivado com cana-de-açúcar com e sem queima da palhada. Revista Brasileira de Ciência do Solo, Viçosa, v. 24, n. 1, p. 201-207, 2000.

MIRANDA, J.; LIOVANDO, M. C.; RUIZ, H. A.; EINLOFT, R. Composição química da solução de solo sob diferentes coberturas vegetais e análise de carbono orgânico solúvel no deflúvio de pequenos cursos de água. Revista Brasileira de Ciência do Solo, Viçosa, v. 30, n. 4, p. 633-647, 2006.

MORETI, D.; ALVES, M. C.; VALÉRIO FILHO, W. V.; CARVALHO, M. de P. e. Atributos químicos de um Latossolo Vermelho sob diferentes sistemas de preparo, adubações e plantas de cobertura. Revista Brasileira de Ciência do Solo, Viçosa, v. 31, n. 1, p. 167-175, 2007.

OLIVEIRA JÚNIOR, A. C.; SILVA, C. A.; CURI, N.; LIMA, J. M.; RANGEL, O. J. R. Formas e quantidades de carbono em lixiviados de Latossolos vermelhos sob influência de calcário e fósforo. Revista. Brasileira de Ciência do Solo, Viçosa, v. 32, n. 3, p. 1261-1271, 2008.

PEREIRA, M. G.; LOSS, A.; BEUTLER, J. S.; TORRES, J. L. R. Carbono, matéria orgânica leve e fósforo em diferentes sistemas de manejo do solo. Pesquisa Agropecuária Brasileira, Brasilia, v.45, n. 5, p. 508-514, 2010.

PEREIRA, M. G.; LOSS, A.; BEUTLER, S. J. ; TORRES, J. L. R. Granulometric and humic fractions carbon stocks of soil organic matter under no-tillage system in Uberaba, Brazil. Tropical and Subtropical Agroecosystems, Yucatan, v. 15, n. 1, p. 1-13, 2012.

PRIMAVESI, A. O manejo ecológico do solo. 4. ed. São Paulo: Nobel, 1982. 541 p.

RESCK, D. V. S.; FERREIRA, E. A. B.; FIGUEIREDO,
C. C.; ZINN, Y. L. Dinâmica da matéria orgânica no Cerrado. In: SANTOS, G. A.; SILVA, L. S.; CANELLAS, L. P.; CAMARGO, F. O. (Ed.). Fundamentos da matéria orgânica do solo: ecossistemas tropicais e subtropicais. 2. ed. Porto Alegre: Metrópole, 2008. p. 359-417.

RIBAS, L. M.; BALDOTTO, M. A.; CANELLAS, L. P.; REZENDE, C. E. Qualidade e mobilidade da matéria orgânica de sistemas adjacentes à lagoa de cima, Campos dos Goytacazes-RJ. Geochimica Brasiliensis, Rio de Janeiro, v. 22, n. 2, p. 103-112, 2008.

ROSSI, C. Q.; PEREIRA, M. G.; GIACOMO, S. G.; BETTA, M.; POLIDORO, J. C. Frações húmicas da matéria orgânica do solo cultivado com soja sobre palhada de braquiária e sorgo. Bragantia, Campinas, v. 70, n. 3, p. 622-630, 2011.

SANO, E. E.; FERREIRA, L. G.; ASNER, G. P.; STEINKE, E. T. Spatial and temporal probabilities of obtaining cloud-free Landsat images over the Brazilian tropical savanna. International Journal of Remote Sensing, Hong Kong, v. 28, n. 12, p. 2739-2752, 2007.

SANTOS, H. G.; JACOMINE, P. K. T.; ANJOS, L. H. C.; OLIVEIRA, V. A.; OLIVEIRA, J. B.; COELHO, M. R.; LUMBRERAS, J. F.; CUNHA, T. J. F. (Ed.). Sistema brasileiro de classificação de solos. 2. ed. Rio de Janeiro: Embrapa Solos, 2006. 306 p.

SIQUEIRA NETO, M. Estoques de carbono e nitrogênio do solo com diferentes usos no Cerrado em Rio Verde, GO. 2006. Tese (Doutorado em Agricultura) - Universidade de São Paulo, Piracicaba.

SIQUEIRA NETO, M. M.; PICCOLOPICCOLO, M. C.; SCOPEL, E.; COSTA JUNIOR, C.; CERRI, C. C.; CERRI, C. C.; BERNOUX, M. Carbono total e atributos químicos com diferentes usos do solo no Cerrado. Acta Scientiarum Agronomy, Maringá, v. 31, n. 4, p. 709-717, 2009.

SISTI, C. P. J.; SANTOS, H. P. dos; KOHHANN, R.; ALVES, B. J. R.; URQUIAGA, S.; BODDEY, R. M. Change in carbon and nitrogen stocks in soil under 13 years of conventional or zero tillage in southern Brazil. Soil and Tillage Research, Amisterdan, v. 76, n. 1, p. 3958, 2004.

SOUZA, W. J. O.; MELO, W. J. Matéria orgânica em um Latossolo submetido a diferentes sistemas de produção de milho. Revista Brasileira de Ciência do Solo Amisterdan, v. 27, n. 6, p. 1113-1122, 2003.

STEVENSON, F. J. Humus chemistry. New York: John Willey \& Sons, 1994. 496 p.

SWIFT, R. S. Organic matter characterization. In: SPARKS, D. L. (Ed.). Methods of soil analysis. Part 3. Madison: America Society of Agronomy, 1996. p. 1011- 
1020. (Soil Science Society of America Book Series, 5).

TORRES, J. L. R.; PEREIRA, M. G.; ANDRIOLI, I.; POLIDORO, J. C.; FABIAN, A. J. Decomposição e liberação de nitrogênio de resíduos culturais de plantas de cobertura em um solo de Cerrado. Revista Brasileira de Ciência do Solo, Viçosa, v. 29, n. 4, p. 609-618, 2005.

URQUIAGA, S.; JANTALIA, C. P.; ZOTARELLI, L.; ALVES, B. J. R.; BODDEY, R. M. Manejo de sistemas agrícolas para o seqüestro de carbono no solo. In: AQUINO, A. M.; ASSIS, R. L. (Org.). Conhecimentos e técnicas avançadas para o estudo dos processos da biota no sistema solo-planta. Brasília: Embrapa, 2005. p. 257273.

YEOMANS, J. C.; BREMNER, J. M. A rapid and precise method for routine determination of organic carbon in soil. CommunicationsSoil Science and Plant Analysis, New York, v. 19, n. 13, p. 1467-1476, 1988.

ZECH，W.; SENESI, N.; GUGGENBERGER, G.; KAISER, K.; LEHMANN, J.; MIANO, T. M.; MILTNER, A.; SCHROTH, G. Factors controlling humification and mineralization of soil organic matter in the tropics. Geoderma, Sydney, v. 79, n. 1-4, p. 117-161, 1997. 